\title{
Research and Application of Open-Off Cut Roof Cutting Pressure Releasing Technology
}

\author{
Xingen Ma $\mathbb{D}^{1,2}$ Manchao He, ${ }^{2}$ Weidong Li, ${ }^{1}$ Yilong Wang, ${ }^{1}$ Lifeng Li, ${ }^{3}$ Xiaohu Sun, \\ Yongyuan $\mathrm{Li}^{1}{ }^{1}$ Leiyu $\mathrm{Gu},{ }^{1}$ and Xingfeng Sha ${ }^{1}$ \\ ${ }^{1}$ Huaneng Coal Technology Research Co., Ltd., China Huaneng, Beijing 100070, China \\ ${ }^{2}$ State Key Laboratory for Geomechanics \& Deep Underground Engineering, China University of Mining \& Technology, \\ Beijing 100083, China \\ ${ }^{3}$ School of Architecture and Civil Engineering, Guizhou University of Engineering Science, Bijie, Guizhou 551700, China
}

Correspondence should be addressed to Xingen Ma; 294185559@qq.com

Received 14 March 2021; Accepted 25 April 2021; Published 12 May 2021

Academic Editor: Zizheng Zhang

Copyright (C) 2021 Xingen Ma et al. This is an open access article distributed under the Creative Commons Attribution License, which permits unrestricted use, distribution, and reproduction in any medium, provided the original work is properly cited.

\begin{abstract}
The first weighting control is one of the difficult problems that cannot be avoided in the safe and efficient production of longwall mining face. To optimize the existing pressure releasing technology of open-off cut, the open-off cut roof cutting pressure releasing (OCRCPR) technology is put forward on the basis of roof cutting pressure releasing gob-side entry retaining (RCPRGER) technology. Firstly, the mechanism of the technology and the design method of related key parameters are summarized. Then the pressure releasing effect of OCRCPR and the stress environment change under this technology are analyzed by mechanics calculation and numerical simulation, respectively, which verify the feasibility of the OCRCPR technology from the theoretical level. Finally, a test mining face is taken as an example to implement the field test. The field test results show that the OCRCPR can effectively shorten the first weighting step and weaken the first weighting strength and has a good pressure releasing effect.
\end{abstract}

\section{Introduction}

In 1950s, the world first longwall mechanized mining coal was established in Britain. This mining technology has the advantages of high mining efficiency, high resource recovery rate, and convenient production continuity. Since China began to learn the longwall mining method from the Soviet Union during the First Five-Year Plan period, after many years of experiment and promotion, combined with the coal seam occurrence conditions in China, the longwall mining technology with Chinese characteristics has been developed [1].

However, in the process of longwall mining operation, the weighting control of the main roof is one of the unavoidable problems about safety [2]. In particular, the first weighting of the working face is the most violent strata behavior process which is difficult to control. For quite some time, many researchers have studied the mechanism of rock pressure in this process and have got a lot of achievements in the prediction of first weighting step, the analysis of the main roof instability process, the prevention and control of roof leakage and wall caving and so on. For examples, Dai Xingguo has established the calculation method of main roof first weighting step according to the damage limit analysis of plate structure [3, 4]. Huang Qingxiang analyzed the stability of roof structure and its control ways during the first weighting period based on the "S-R" theory [2]. Existing research results give many references for the prevention and control of first weighting in longwall face, but its prevention and control strategy mainly is weighting forecast in advance and passive support reinforcement, which has not really changed the weighting structure of the main roof and has great limitations in practical application.

In recent years, with the deepening of theoretical research and the improvement of practical level, the roof presplitting blasting technology of open-off cut appeared in the prevention and control of working face first weighting [5-7]. Existing presplitting blasting technologies on open-off 
cut roof realize the prevention and control of first weighting to a certain extent by actively changing the shape and structure of roof, but there are still many shortcomings in the process of field implementation: first, the direction of presplitting blasting is difficult to control, the efficiency of roof breaking is low, and it is easy to cause damage to the original support of open-off cut; second, the implementation process is complicated, as it often needs to carry out the blast on open-off cut roof after the hydraulic supports, which will affect the mining progress at the initial stage.

Therefore, taking a test working face as an example, this paper draws lessons from the theory of roof cutting entry retaining (RCPRGER) put forward by academician $\mathrm{He}$ Manchao and studies the open-off cut roof cutting (OCRCPR) technology based on tension blasting [8]. The research results can further optimize the means of prevention and control of first weighting in longwall face, improve the pressure releasing efficiency of first weighting, and expand the application scope and advantages of longwall mining.

\section{The OCRCPR Technology}

Existing RCPRGER technology can change the retained entry roof structure actively through the presplitting blasting and take use of the gangue collapsed from lower layers of goaf roof to realize the entry retaining without coal pillar or material, as shown in Figure 1(b) $[9,10]$. Based on above, in order to reduce the first weighting strength of main roof artificially on the strike direction, the OCRCPR technology is put forward, and the roof structure of open-off cut can also be changed actively by presplitting blasting, as shown in Figure 1(c).

\subsection{Open-Off Cut Pressure Releasing Mechanism and Related} Design. In the mining early stage of traditional longwall working face, the one end of goaf roof is supported by the coal wall on strike section, and the other end is supported by the hydraulic supports of working face and the coal wall in front of open-off cut, showing a fixed beam state (as shown in Figure 2) $[11,12]$. Therefore, the length of roof suspension behind working face is usually longer before the first weighting, and the first weight strength is also usually greater, which is easy to cause damage to the hydraulic supports and other equipment of the working face.

When using OCRCPR technology to carry out the presplitting roof cutting on the open-off cut roof along the inclination direction of mining face, in the mining early stage, the goaf roof presents a cantilever beam structure on the strike direction, and the goaf roof is only supported by the hydraulic supports and the front coal wall (as shown in Figure 3). At this time, compared with the roof uncut condition, the first weighting step of working face will be greatly shortened, and the first weighting strength can also be greatly reduced.

Referring to the practical experience, the formula of roof cutting height preliminary design is shown as Formula (1). When there are more than one strata layer about cutting roof, the roof bulking coefficient can be got through weighted calculation based on thickness of each layer as follows [13]:

$$
\begin{aligned}
H_{F} & =\frac{\left(H_{M}-\Delta H_{1}-\Delta H_{2}\right)}{(K-1)}, \\
K & =\sum_{i=1}^{n} K_{i} \frac{D_{i}}{H_{M}}
\end{aligned}
$$

where $H_{F}$ is the cutting height, $H_{M}$ is the coal seam mining height, $\Delta H_{1}$ is the roof subsidence volume, $\Delta H_{2}$ is the floor heave volume, $K$ is the bulking coefficient, $n$ is the number of rock layers in the roof cutting range, $n \geq 1, D_{i}$ is the thickness of each rock layer, $1 i \leq n$, and $K_{i}$ is the bulking coefficient of each rock layer, $1 i \leq n$.

The roof cutting angle design of open-off cut includes three cases: backward inclination, forward inclination, and vertical inclination, as shown in Figure 4. (a) Under the same roof cutting height, the amount of gangue in the roof cutting range is larger under backward inclination condition, which is conducive to the filling of the goaf. Therefore, choosing the backward inclination roof cutting design can reduce the cutting height to a certain extent under the thick coal seam. (b) Forward inclination design is more conducive to roof collapse within the cutting range, so when the thickness of coal seam is small and the cutting height is low, roof collapse can be promoted earlier through the design of this scheme. (c) The advantage of vertical roof cutting is easy to construct. Usually the space behind supports in the open-off cut is limited, and the vertical cutting has a lower space demand and whose construction adaptability is better.

2.2. Bidirectional Concentrated Tension Blasting Technology. In the OCRCPR technology, the directional roof presplitting is also realized by the bidirectional concentrated tension blasting technology. This blasting technology can make the explosive blasting energy directional transmit, and the principle of bidirectional concentrated tensile blasting is shown in Figure 5 [14, 15].

In the field application of this study, the pipe size of blasting is $\varphi 36.5 \mathrm{~mm} \times 1500 \mathrm{~mm}$, and pipes can be connected one by one. The best blasting parameters can be determined by field blasting test.

\section{Effect Analysis of Roof Cutting Pressure Releasing}

The schematic diagram of entry retaining technology with roof cutting is shown in Figure 1(b). To further study the pressure releasing effect of open-off cut roof cutting on above, this section uses two methods, mechanical calculation and numerical simulation, to analyze the first weighting of mining face and the stress environment.

\subsection{Calculation about First Weighting}

3.1.1. Open-Off Cut Roof Uncut Condition. Under the openoff cut roof uncut condition, the first weighting process of roof is shown in Figure $2[16,17]$. Because the tendency 


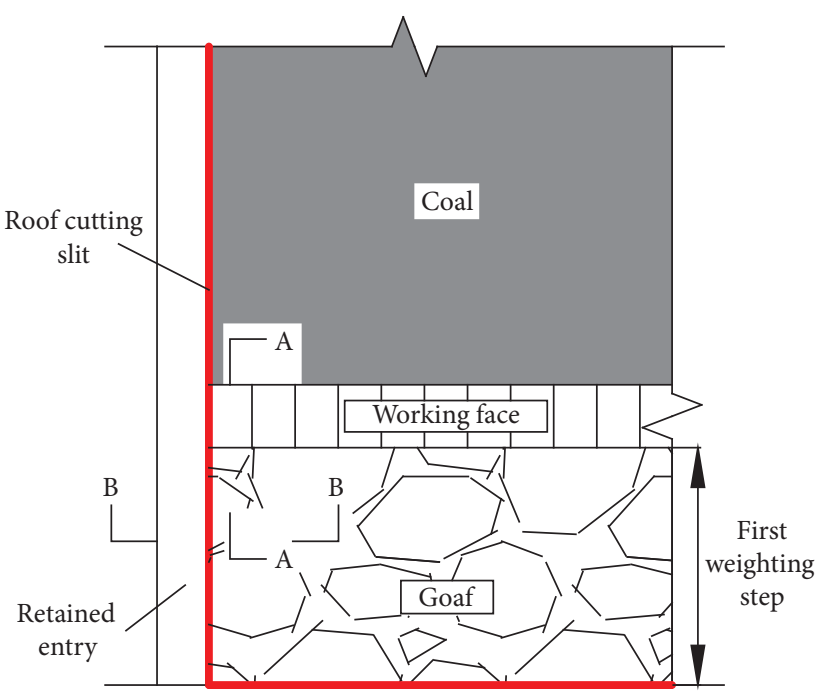

(a)

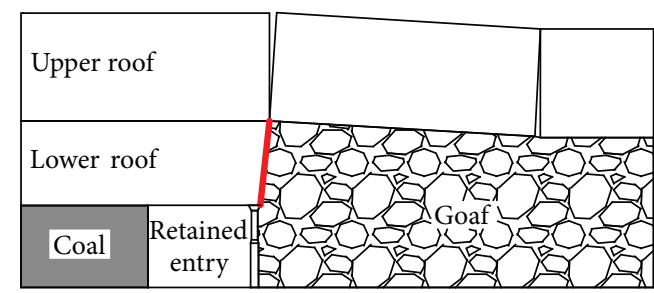

(b)

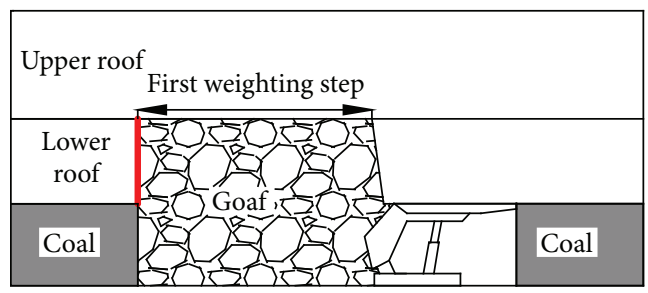

(c)

FIGURE 1: Schematic diagram of roof cutting in retained entry and open-off cut: (a) plane of roof cutting in retained entry and open-off cut; (b) section map of entry retaining roof cutting (section B-B); (c) section map of open-off cut roof cutting (section A-A).

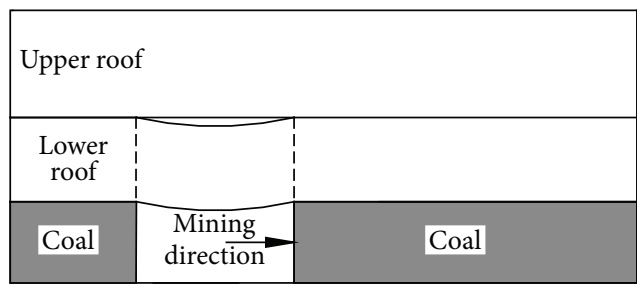

(a)

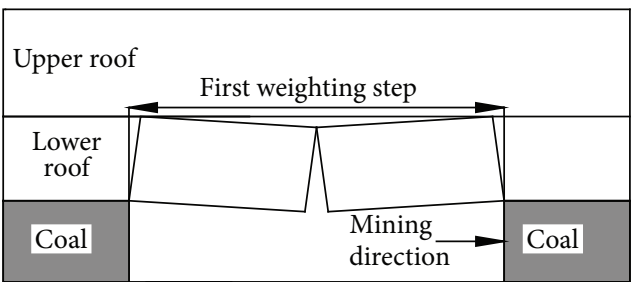

(b)

FiguRe 2: Working face first weighting under traditional condition: (a) roof structure before first weighting; (b) roof structure at first weighting.

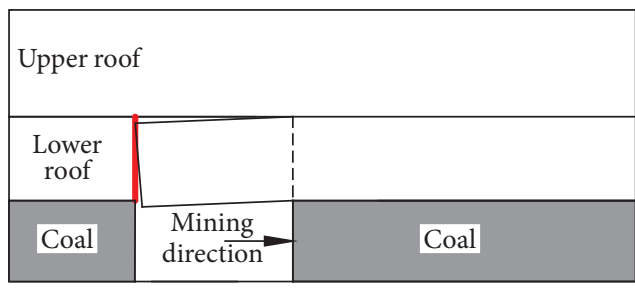

(a)

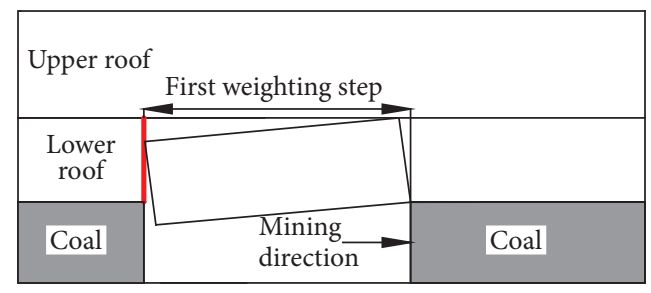

(b)

FIGURE 3: Working face first weighting under open-off cut roof cutting condition: (a) roof structure before first weighting; (b) roof structure at first weighting. 


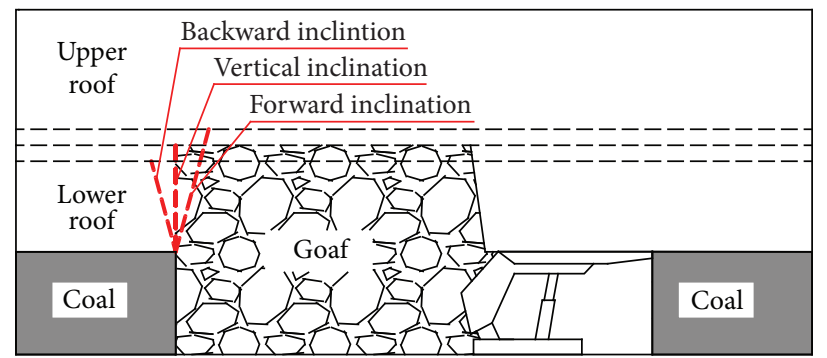

FIGURE 4: Roof cutting angle design of open-off cut.

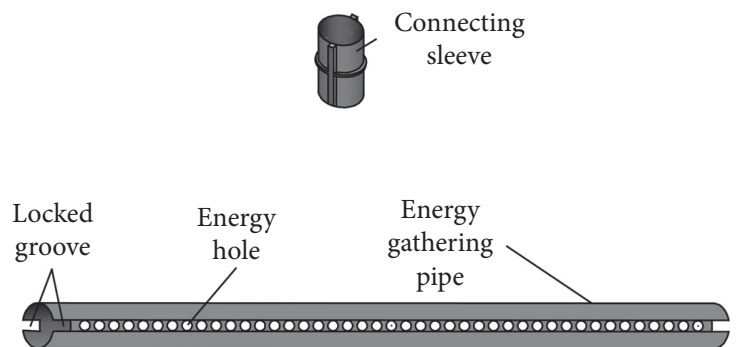

(a)

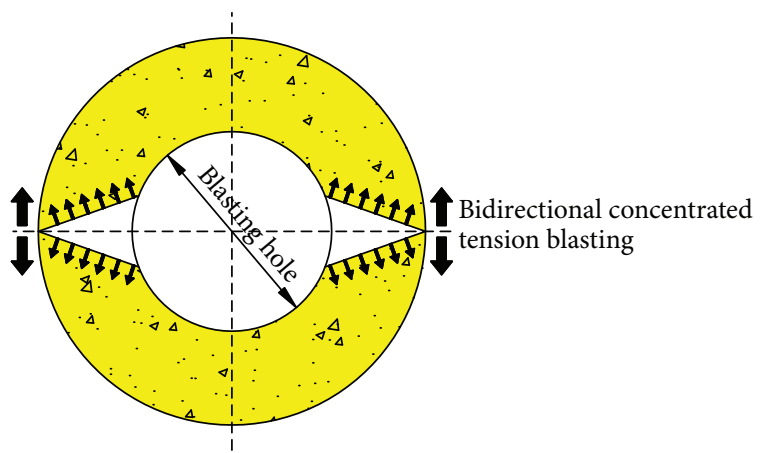

(b)

FIGURE 5: Devices and principle of bilateral cumulative tensile blasting: (a) energy gathering pipe and connecting sleeve; (b) mechanism model (Figure 5 is reproduced from Xingen Ma et al.).

length of working face is much longer than the weighting step of strike direction, the lower roof before collapse at the mining early stage can be seen as a fixed beam state, whose stress analysis is shown in Figure 6.

According to the stress analysis above, the following can be got:

$$
\left\{\begin{array}{l}
R_{1}=R_{2}=\frac{q L}{2} \\
M_{1}=M_{2}=-\frac{1}{12} q L^{2}, \\
M_{x}=R_{1} x-\frac{q x^{2}}{2}+M_{1}=\frac{q}{12}\left(6 L x-6 x^{2}-L^{2}\right) .
\end{array}\right.
$$

At both ends of the fixed beam (when $x=0$ or $x=L$ ), $M_{\max }=-q L^{2} / 12$; at the middle of the fixed beam (when $x=L$ / 2), $M=q L^{2} / 24$. The normal stress at any point is

$$
\sigma=\frac{M y}{J_{z}},
$$

where $M$ is the moment of the section where the point is located, $y$ is the distance from the point to the center axis, and $J_{z}$ is the end distance of the symmetrical center axis. Because the bending moment is the highest at both ends of the fixed beam, the tensile stress is also the highest at there:

$$
\sigma_{\max }=\frac{q L^{2}}{2 h^{2}} .
$$

When $\sigma_{\max }=R_{T}$, that is, when the normal stress of the stratum reaches its ultimate tensile strength, the stratum will be fractured. At this time, the ultimate span of the roof (first weighting step) is

$$
L=h \sqrt{\frac{2 R_{T}}{q}},
$$

where $L$ is the first weighting step, $h$ is the thickness of rock beam, $R_{T}$ is the tensile strength of rock beam, and $q$ is the uniform load of rock beam and its overlying rock mass.

When the working face is weighting, the main stress of hydraulic support is from the gravity of the falling lower roof. According to this, the weighting strength can be estimated according to the following formula:

$$
P=\frac{L h \rho}{l_{y}}=\frac{h^{2} \rho}{l_{y}} \sqrt{\frac{2 R_{T}}{q}},
$$

where $\rho$ is the density of rock beam and $l_{y}$ is the support length of single hydraulic support.

3.1.2. Open-Off Cut Roof Cutting Condition. Under the open-off cut roof cutting condition, the first weighting process of roof is shown in Figure 3 [17]. At this time, the lower roof before collapse at the mining early stage can be 


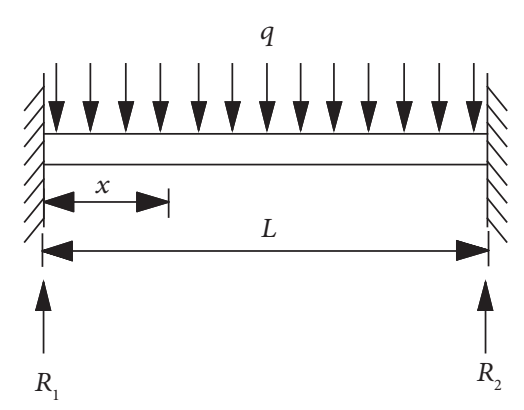

(a)

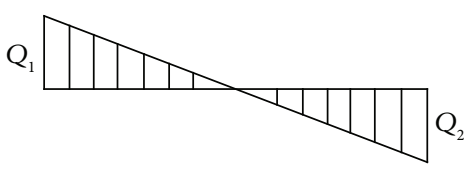

(b)

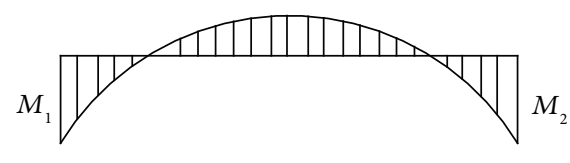

(c)

Figure 6: Stress analysis of fixed beam: (a) mechanical model; (b) shear stress diagram; (c) bending moment diagram.

seen as a cantilever beam state, whose stress analysis is shown in Figure 7.

According to the stress analysis above, the bending moment on any section of the cantilever beam is

$$
M_{x}=-\frac{1}{2}(q l-x)^{2} .
$$

The maximum bending moment occurs at the fixed position of the beam, namely,

$$
M_{\text {max }}=M_{1}=-\frac{q L^{2}}{2} .
$$

The tensile stress here is the maximum:

$$
\sigma_{\max }=\frac{3 q L^{2}}{2 h^{2}},
$$

when $\sigma_{\max }=R_{T}$, that is, when the normal stress of the stratum reaches its ultimate tensile strength, the stratum will be fractured. At this time, the ultimate span of the roof (first weighting step) is

$$
L=h \sqrt{\frac{R_{T}}{3 q}} .
$$

The weighting strength can be estimated as follows:

$$
P=\frac{L h \rho}{l_{y}}=\frac{h^{2} \rho}{l_{y}} \sqrt{\frac{R_{T}}{3 q}} .
$$

We can see that the structure of lower roof changed from fixed beam to cantilever beam in the mining early stage after the open-off cut roof cutting, and then the first weighting step became shorter and first weighting strength became weaker.

3.2. Stress Evolution Analysis of Surrounding Rock. Based on the geological conditions of test mining face, the surrounding rock stress evolution process with or without open-off cut roof cutting at the mining initial stage will be simulated by using FLAC 3D numerical simulation software $[18,19]$. Modeling size is $200 m \times 170 m \times 50 \mathrm{~m}$, including roof $30 \mathrm{~m}$, coal seam $3 \mathrm{~m}$, and floor $17 \mathrm{~m}$. In this model, working face simulation strike length is $160 \mathrm{~m}$, simulation tendency length is $130 \mathrm{~m}$, and simulation entry width is $5 \mathrm{~m}$, as shown in Figure 8. The parameters of each stratum in this model are shown in Table 1, the cutting height is designed as $7.7 \mathrm{~m}$, and the vertical roof cutting is adopted [20].

The numerical simulation results of key section are shown in Figure 9. When mining to footage $0 \mathrm{~m}$, the stress distribution with roof cutting is asymmetrical. Compared with the symmetrically stress distribution under open-off cut roof uncut condition, the peak value of stress concentration in advance is slightly higher. When mining to footage $10 \mathrm{~m}$, the goaf roof collapse under the open-off cut roof cutting condition is more sufficient than that under the roof uncut condition, and the stress peak value in advance of mining face begins to be less than that of roof uncut condition. When mining to footage $20 \mathrm{~m}$ and $40 \mathrm{~m}$, the roof collapse shape is basically stable under the two conditions, and the stress peak value under the open-off cut roof cutting condition is more smaller than that under roof uncut condition. The relationship between the stress concentration peak value and the mining footage under the two conditions in the early mining stage is further sorted out as shown in Figure 10, which shows that the peak values are all equal to $31.0 \mathrm{MPa}$ under two conditions when mining to $6.8 \mathrm{~m}$; the stress concentration peak value under open-off cut roof cutting is slightly higher before mining to $6.8 \mathrm{~m}$; the stress concentration peak value under open-off cut roof cutting is smaller after mining to $6.8 \mathrm{~m}$, and the difference increases gradually with the working face advancing within the first weighting step.

Through the above analysis, the open-off cut roof cutting can cut off the support to goaf roof of coal pillar behind the open-off cut, and then the advanced stress concentration strength of working face is higher at initial mining stage. But with the mining, the goaf roof is easier to collapse under the roof cutting condition, and the advanced stress concentration strength of working face turns to be smaller than that of roof uncut condition.

\section{Field Condition and Cut Top Design}

On the basis of the above mechanism and effect analysis through theoretical calculation and numerical simulation, taking 8304 mining face of Tashan coal mine as an example, the field test of OCRCPR technology is carried out to verify the feasibility and practicability. 


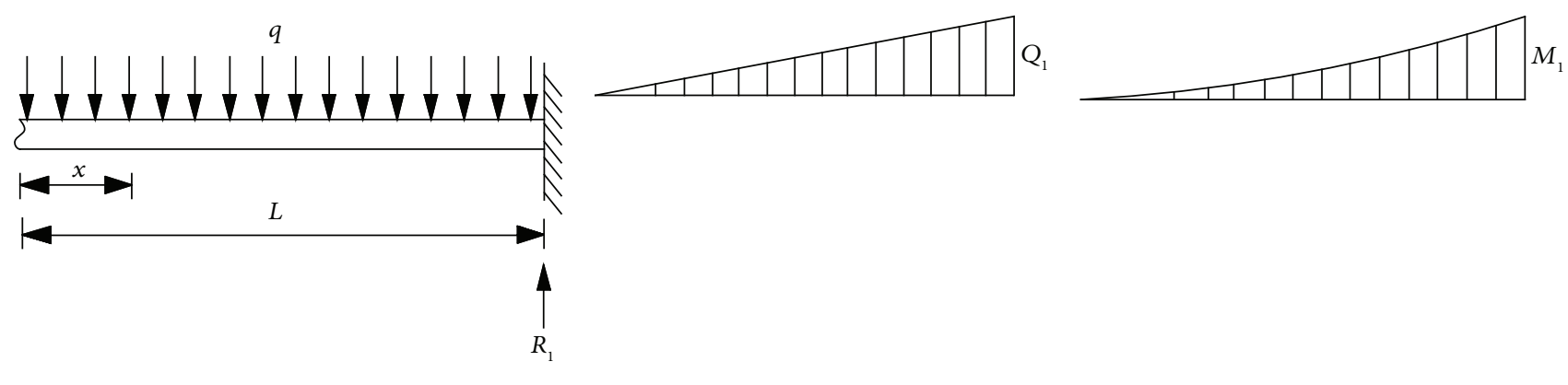

(a)

(b)

(c)

FIgURE 7: Stress analysis of cantilever beam: (a) mechanical model; (b) shear stress diagram; (c) bending moment diagram.
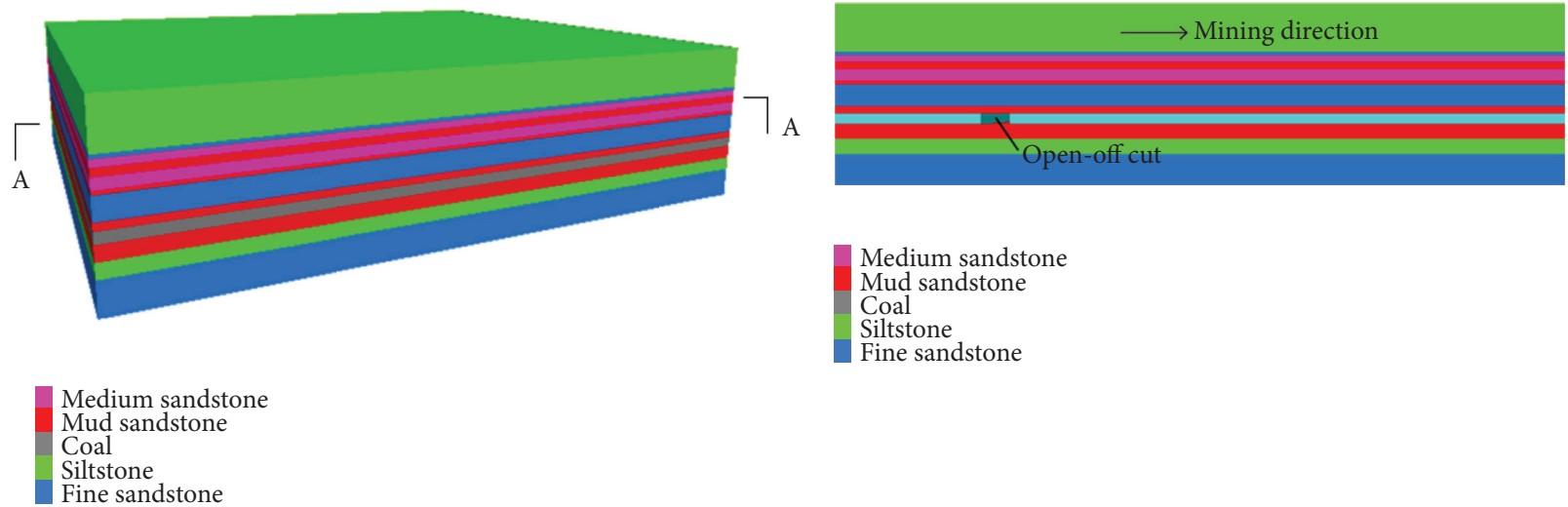

Medium sandstone

Mud sandstone

Coal

Siltstone

Fine sandstone

Medium sandstone

Coal

Fine sandstone

(a)

(b)

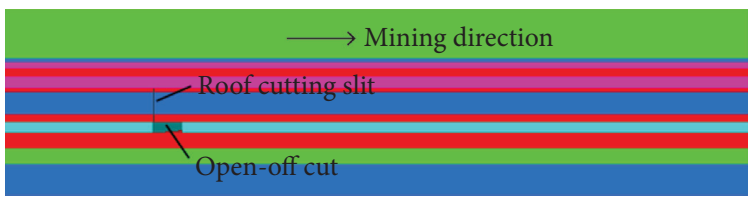

Medium sandstone

Mud sandstone

Coal

Siltstone

Fine sandstone

(c)

Figure 8: Numerical simulation model: (a) three-dimensional model; (b) A-A section under open-off cut roof uncut condition; (c) A-A section under open-off cut roof cutting condition.

TABle 1: Physical and mechanical parameters of each rock layer.

\begin{tabular}{lcccccc}
\hline Lithology & Density/kN/m & Tensile strength/MPa & Internal friction angle/ ${ }^{\circ}$ & Cohesion/MPa & $\begin{array}{c}\text { Bulk modulus/GPa } \\
\text { modulus/GPa }\end{array}$ \\
\hline Medium & 25 & 8.4 & 33 & 2.6 & 11.49 & 7.26 \\
sandstone & 23 & 3.2 & 28 & 0.2 & 0.20 & 0.15 \\
Mudstone & 13 & 3.3 & 29 & 0.2 & 0.35 & 0.18 \\
Coal & 23 & 4.3 & 32 & 0.8 & 2.11 & 1.86 \\
Siltstone & 24 & 7.3 & 32 & 1.0 & 3.81 \\
Fine sandstone & & & & & & 3.05 \\
\hline
\end{tabular}

4.1. Engineering Overview. The key information of test mining face is shown in Table 2 and Figure 11 [21].

As test working face, 8304 working face adopts comprehensive mechanized mining method, and its planned daily mining speed is $10 \mathrm{~m}$. The auxiliary haulage entry of this working face is designed to be retained by roof cutting and still used as auxiliary haulage entry for 8305 working face. In order to reduce the working face first weighting 


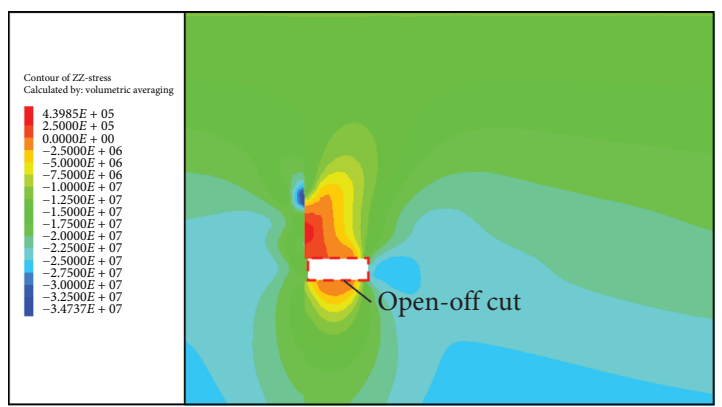

(1)

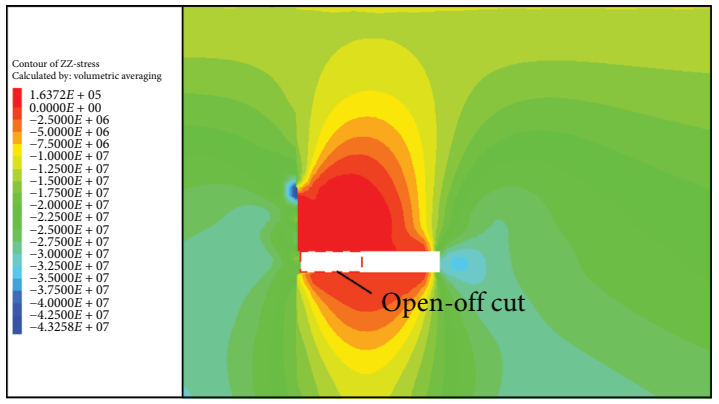

(1)

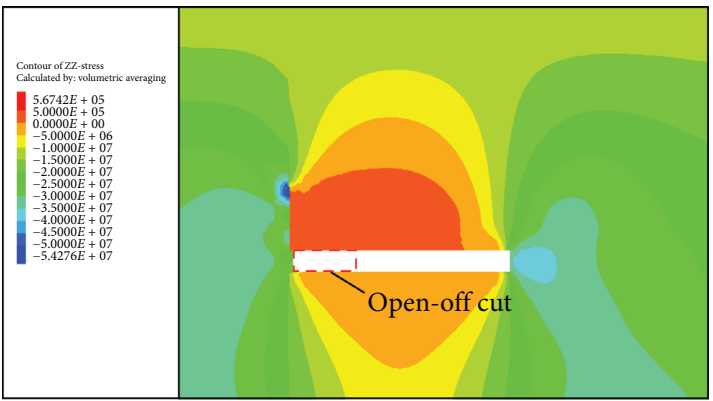

(1)

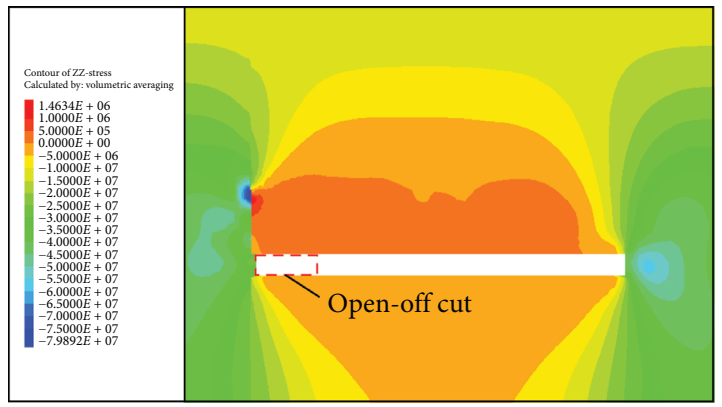

(1)

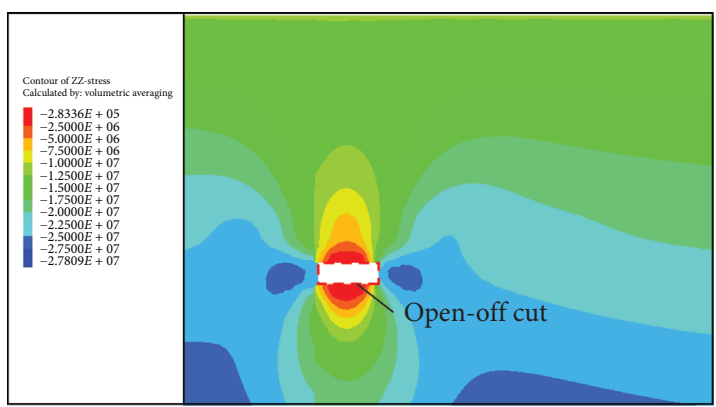

(2)

(a)

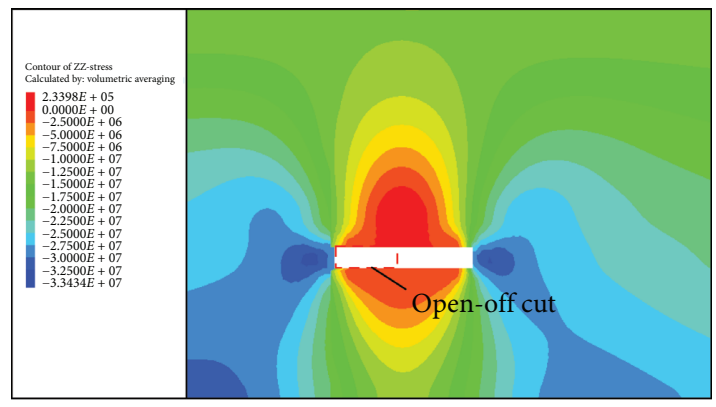

(2)

(b)

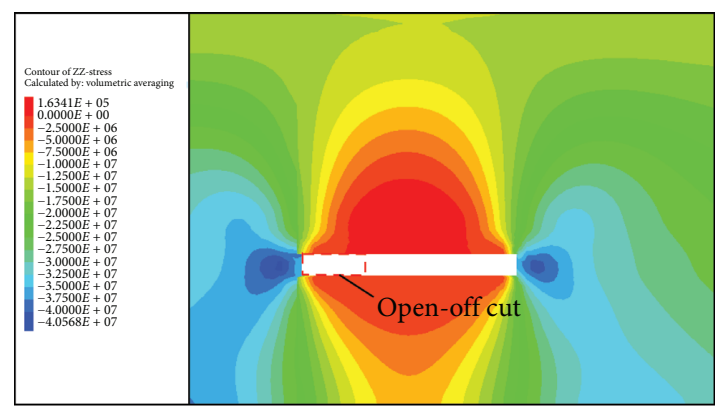

(2)

(c)

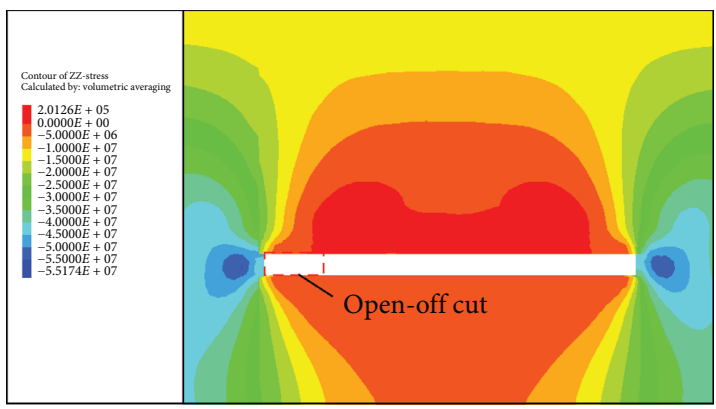

(2)

(d)

FIgURE 9: Numerical simulation results: (a) mining to footage 0 (m) (1) open-off cut roof cutting condition; (2) open-off cut roof uncut condition; (b) mining to footage $10(\mathrm{~m})$ (1) open-off cut roof cutting condition; (2) open-off cut roof uncut condition; (c) mining to footage 20 (m) (1) open-off cut roof cutting condition; (2) open-off cut roof uncut condition; (d) mining to footage 40 (m) (1) open-off cut roof cutting condition; (2) open-off cut roof uncut condition. 


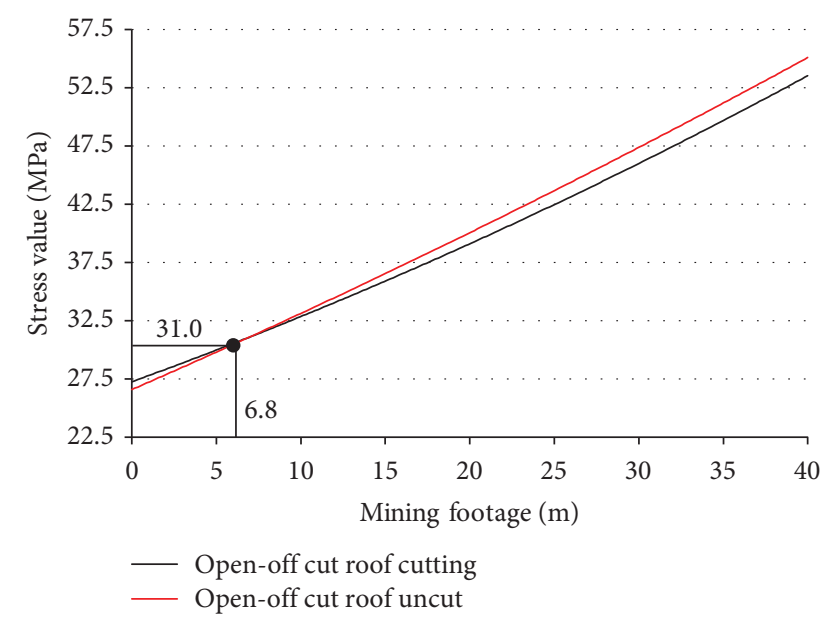

FIGURE 10: Comparison of stress concentration peaks in advance of working face.

strength and promote the rapid stability of retained entry initial section, the OCRCPR test is carried out on 8304 working face.

4.2. Open-Off Cut Roof Cutting Design. The roof cutting height can be calculated to be $7.5 \mathrm{~m}$ according to Formula (1) without considering the roof subsidence and floor heave (taking the roof bulking coefficient as 1.41). Comparing with the roof lithological column, the cutting height is adjusted to $7.7 \mathrm{~m}$ [21]. Because the test mining face is medium-thick coal seam working face, the vertical roof cutting design with stronger adaptability and lower construction difficulty is selected. The roof cutting line is arranged at the intersection of the coal pillar behind the open-off cut and whose roof is along the tendency direction of working face. In order to facilitate the construction, after the open-off cut is penetrated and the hydraulic support is arranged, a $1.5 \mathrm{~m}$ wide passage is set up behind the hydraulic supports, and the specific roof cutting design is shown in Figure 12.

4.3. Open-Off Cut Roof Cutting Process. Based on the above design, the hydraulic support with model ZZS10000/20/38 is selected for 8304 working face, and the sectional dimension of the open-off cut is set as $8.0 \mathrm{~m} \times 3.1 \mathrm{~m}$. After the penetration of open-off cut, the hydraulic supports need to be installed firstly, and an enough space should be left behind supports for blasting holes drilling. Then the marking line of the roof cutting is drawn on the open-off cut roof according to design, which serves as the baseline of the blasting holes drilling and roof presplitting blasting (as shown in Figure 13). To ensure the cutting effect of bidirectional concentrated tension blasting, the marking line should be kept as straight as possible along the working face tendency direction.

After the roof cutting height, angle, and position all determined, the roof cutting blasting parameters, including explosive charge weight, blasting hole spacing, and blasting hole amount at single initiation, all need to be further got through field blasting test $[22,23]$. The field blasting test is divided into three steps as shown in Figure 14 [15]. The first step is to carry out single hole blasting test, namely, blasting one hole each time with different explosive charge weight to determine the reasonable charge of a single hole. The second step is to carry out interval hole blasting test, namely, blasting holes each time with different hole spacing and leaving peephole to judge the reasonable spacing. The third step is to carry out continuous hole blasting test, namely, through the harmful gas monitoring to determine the blasting hole amount at single initiation. Through field test, it is determined that the single blasting hole charge structure in 8304 working face is $4+3+3+2$, four energy gathering pipes are filled in each blasting hole, and the sealing length of each hole is $1.7 \mathrm{~m}$ (as shown in Figure 15). The common presplitting effect in peephole is shown as Figure 16, and the average single hole crack rate detected in site is $83.6 \%$.

\section{Engineering Application Analysis}

5.1. Roof Initial Collapse. The 8304 working face not only uses the OCRCPR technology to weaken the first weighting but also uses the entry retaining technology with roof cutting. The roof cutting range of open-off cut is the $107 \mathrm{~m}$ section near entry retaining side, and another $20 \mathrm{~m}$ section without roof cutting is set as the control section (as shown in Figure 17). On one hand, open-off cut roof cutting on the entry retaining side can reduce the first weighting step and strength, which is good for the rapid stability of retained entry initial section; on the other hand, the retained entry can also provide an observation condition for the goaf roof collapse.

Based on the mining experience of the same mining field, it is inferred that the first weighting step of 8304 working face should be within $50-70 \mathrm{~m}$. Therefore, the initial caving of the goaf roof is observed in the retained entry at footage $10 \mathrm{~m}$. When it is behind the working face $20 \mathrm{~m}$, the goaf roof collapse at retained entry side is shown in Figure 18(a). At this time, the immediate roof has collapsed with large areas, but the gangue pile has not yet reached the goaf roof. When it is behind the mining face $40 \mathrm{~m}$, the goaf roof collapse at retained entry side is shown in Figure 18(b). At this time, gangue pile has reached the goaf roof with bulking, and the gangue wall has been formed basically. In the initial mining stage, the open-off cut roof cutting and the entry roof cutting influence the goaf roof collapse at same time. So the goaf roof collapse process at this time does not have the representativeness of the whole mining face in the inclination direction. However, in the further mining and entry retaining process, the gangue wall all formed within the range $35-42 \mathrm{~m}$ behind the working face, and the OCRCPR can promote the roof collapse in the early mining stage and basically eliminate the problem that the goaf roof is difficult to collapse in the early mining stage.

5.2. Monitoring and Analysis of First Weighting. In addition to the direct observation of the roof collapse in the retained entry, this study also verifies the pressure releasing effect to 
TABLE 2: Basic parameters of 8304 working face.

\begin{tabular}{lccc}
\hline Coal seam tdickness/average $(\mathrm{m})$ & $1.80-3.55 / 3.1$ & Deptd $(\mathrm{m})$ & $367-411$ \\
Mining height $(\mathrm{m})$ & 3.1 & Dip angle/average $\left({ }^{\circ}\right)$ & $2 \sim 6 / 4$ \\
Strike lengtd $(\mathrm{m})$ & 670 & Tendency lengtd $(\mathrm{m})$ & 127 \\
Immediate roof/tdickness $(\mathrm{m})$ & Mudstone/1.47 & Immediate floor/tdickness $(\mathrm{m})$ & Mudstone/3.2 \\
Main roof/tdickness $(\mathrm{m})$ & Fine sandstone/3.88 & Main floor/tdickness $(\mathrm{m})$ & Siltstone/3.1 \\
\hline
\end{tabular}

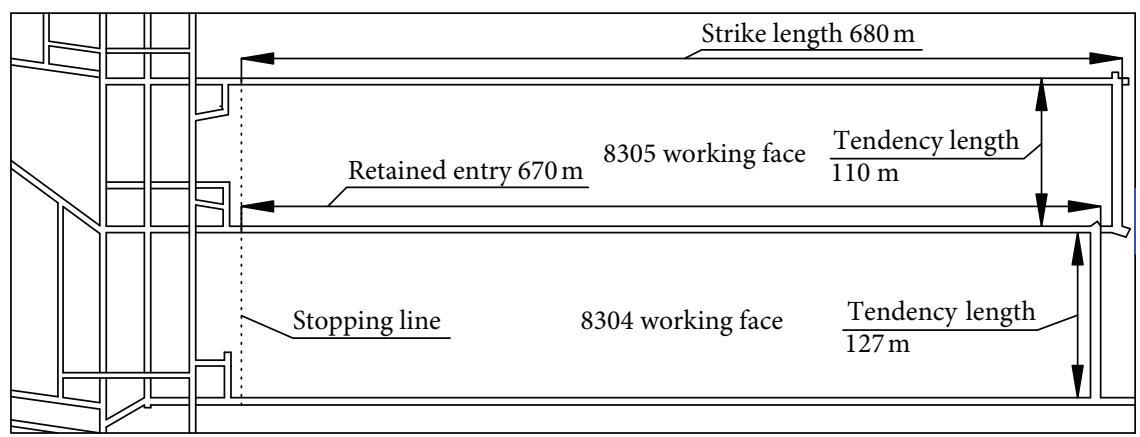

(a)

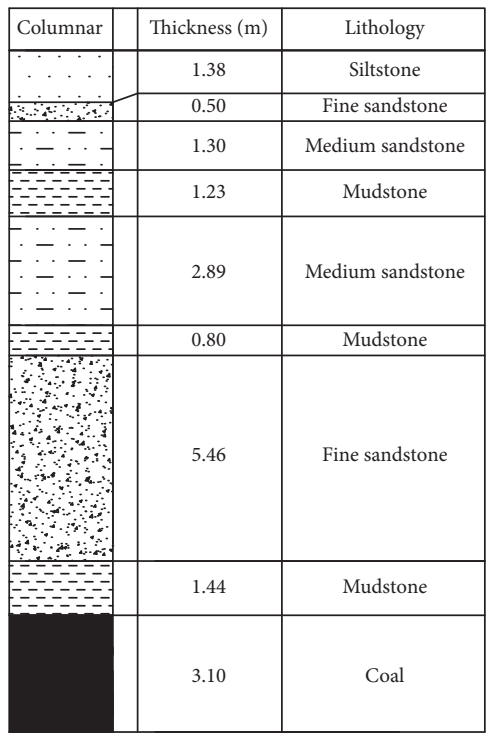

(b)

FIGURE 11: Layout and roof lithologic histogram of 8304 working face.

working face first weighting of the open-off cut roof cutting through the pressure monitoring shown as Figures 17 and 19 [24-26].

The monitoring results of weighting step are shown in Figure 20. Overall, the periodic weighting step is shorter than the first, and that of the retained entry side is longer than the other side. Affected by the roof cutting of open-off cut and entry, the first weighting step of the retained entry side is also smaller. In order to further highlight the pressure releasing effect of open-off cut, the difference between first weighting step and periodic weighting step is arranged in Figure 20(b). The difference between first and periodic weighting step is smaller in the roof cutting range of open-off cut, and the difference is larger in the roof uncut range of open-off cut.

Similarly, the monitoring results of weighting strength are shown in Figure 21. Overall, the periodic weighting strength is lower than the first, and the periodic weighting strength of the retained entry side is smaller. The difference between first weighting strength and periodic weighting strength is arranged in Figure 21(b). The difference between first and periodic weighting strength is smaller in the roof cutting range of open-off cut, and the difference is larger in the roof uncut range of open-off cut. To sum up, the 


\begin{tabular}{|c|c|c|}
\hline Columnar & Thickness (m) & Lithology \\
\hline & 1.28 & Siltstone \\
\hline $4 \quad 4 \quad 4$ & 0.50 & Fine sandstone \\
\hline-------------- & 1.30 & Medium sandstone \\
\hline 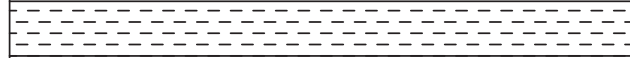 & 1.23 & Mudstone \\
\hline 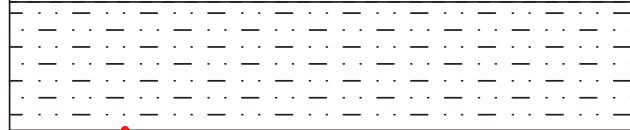 & 2.89 & Medium sandstone \\
\hline (1) & 0.80 & Mudstone \\
\hline 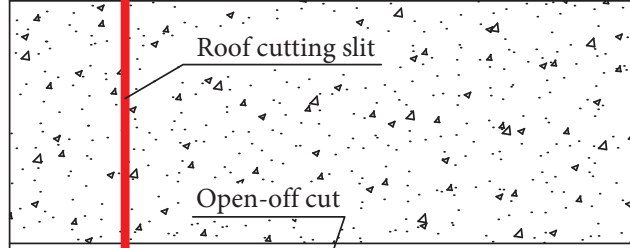 & 5.46 & Fine sandstone \\
\hline $1.5 \mathrm{~m}$ & 1.44 & Mudstone \\
\hline I Mphis & 3.10 & Coal \\
\hline
\end{tabular}

FIGURE 12: Open-off cut roof cutting design of 8304 working face.

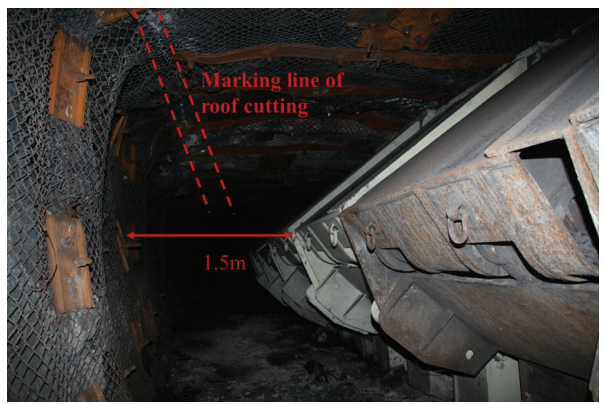

FIgURE 13: Open-off cut roof cutting scene of 8304 working face.

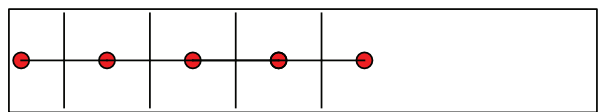

- Blasting hole

(a)

\begin{tabular}{|c|c|c|c|}
\hline $\begin{array}{llll}300 \mathrm{~mm} & & \\
500 & 0 & 0 \\
1 & 2 & 3 & 4\end{array}$ & 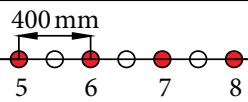 & 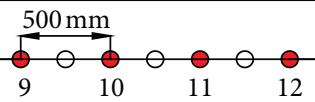 & 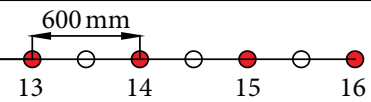 \\
\hline
\end{tabular}

O Peephole

- Blasting hole

(b)

FIGURE 14: Continued. 


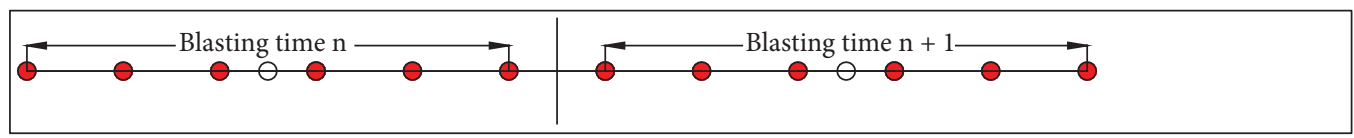

Peephole
Blasting hole

(c)

Figure 14: Blasthole layout of blasting test: (a) single hole blasting test; (b) interval hole blasting test; (c) continuous hole blasting test (Figure 14 is reproduced from Xingen Ma et al.).

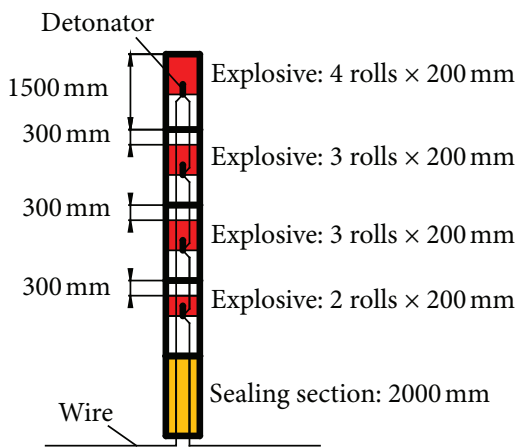

FIGURE 15: Charge structure of explosive rolls.

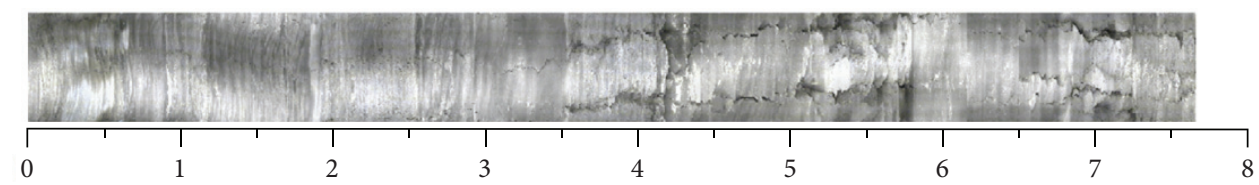

(m)

FIGURE 16: Fissure map of roof cutting blasting.

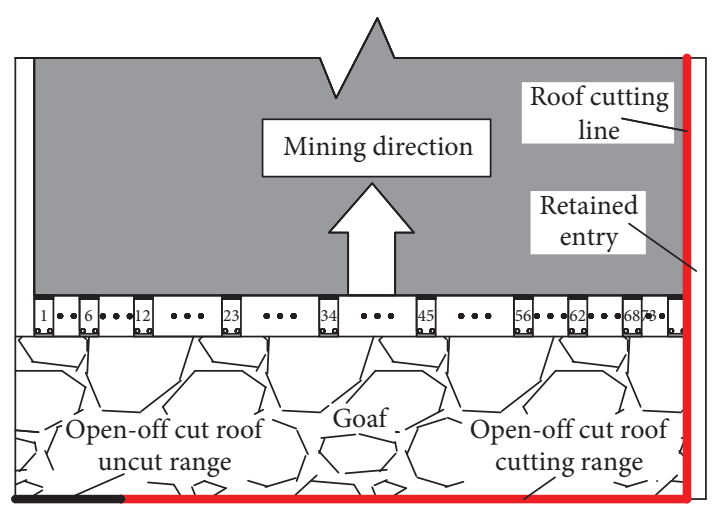

FIgUre 17: Monitoring scheme. 


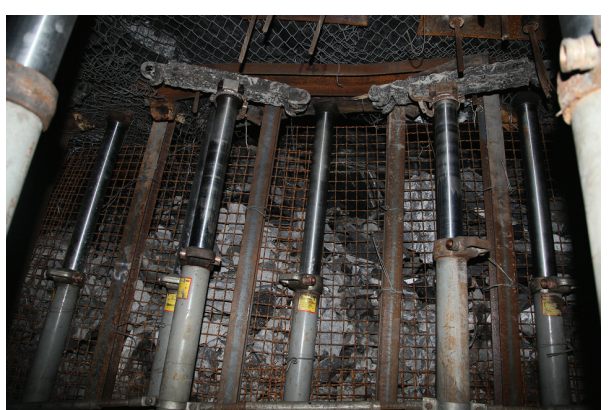

(a)

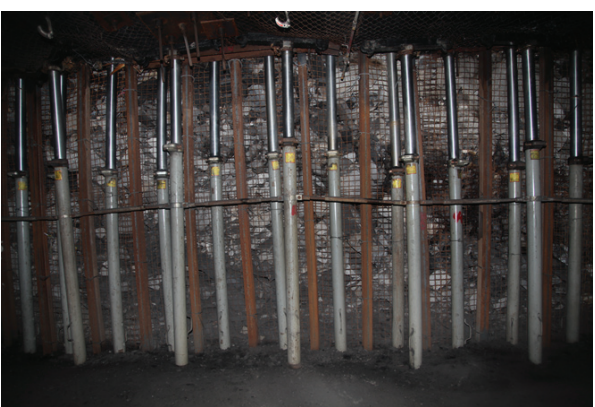

(b)

FIgURE 18: Gangue collapse process at $10 \mathrm{~m}$ footage: (a) behind working face $20 \mathrm{~m}$; (b) behind working face $40 \mathrm{~m}$.

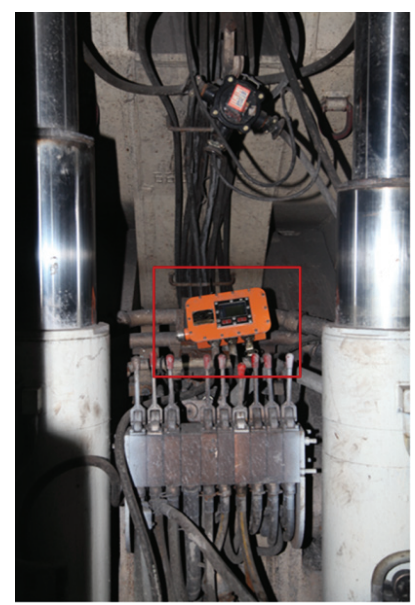

FIGURE 19: Monitoring equipment for hydraulic support.

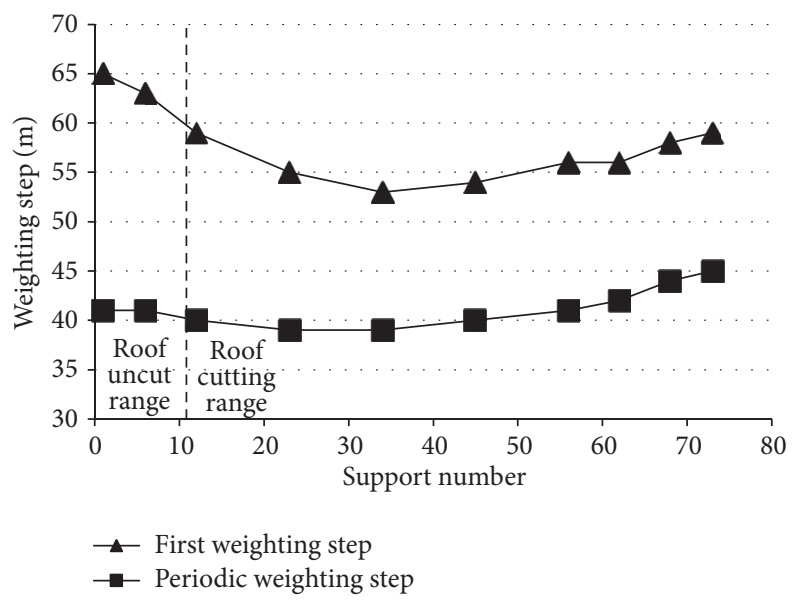

(a)

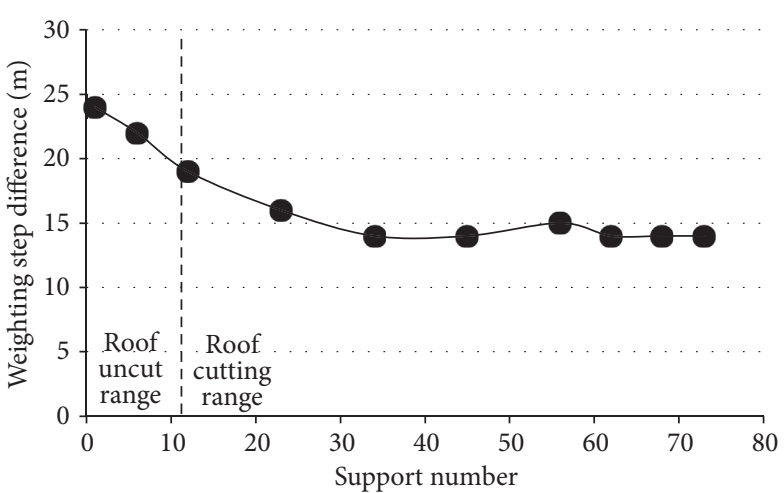

(b)

FIGURE 20: Monitoring result of weighting step: (a) weighting step statistics; (b) weighting step difference. 


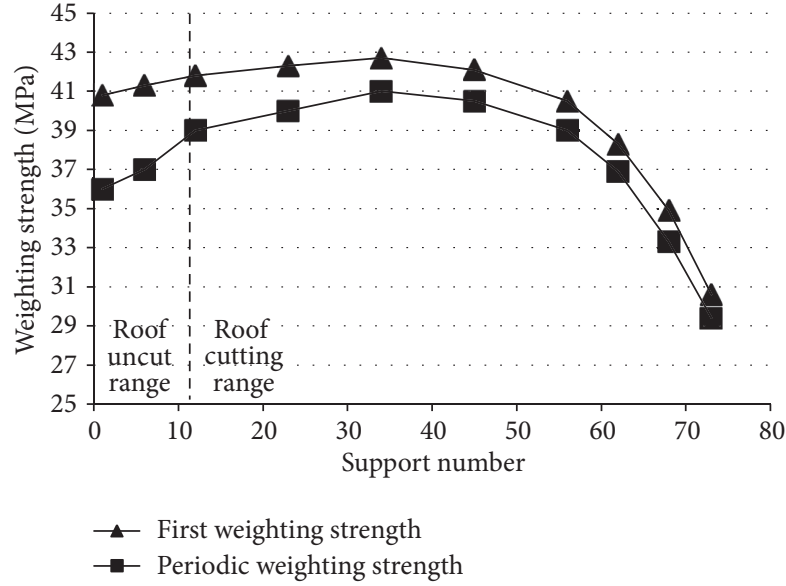

(a)

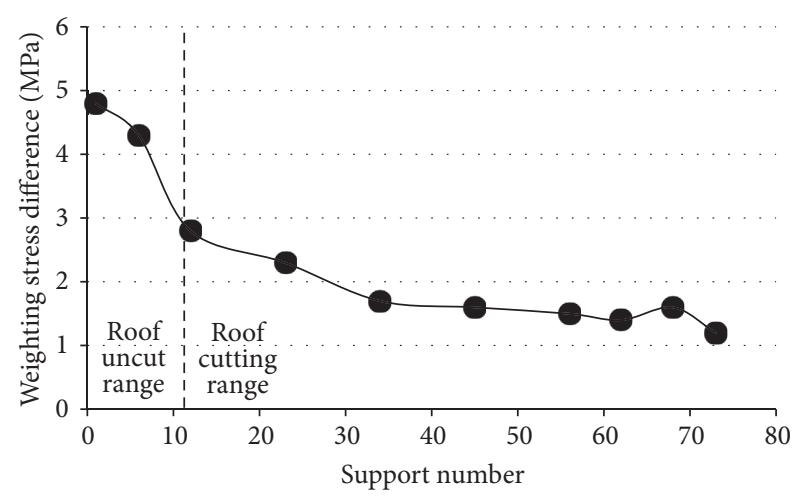

(b)

FIGURE 21: Monitoring result of weighting strength: (a) weighting strength statistics; (b) weighting strength difference.

OCRCPR can effectively shorten the first weighting step and reduce the first weighting strength and has a good pressure releasing effect.

\section{Conclusions}

(1) Based on the entry retaining technology with roof cutting, the pressure releasing technology of open-off cut roof is put forward, namely, changing the roof structure of open-off cut actively by roof presplitting cutting, which can weaken the first weighting strength and shorten the first weighting step of working face artificially on the strike direction.

(2) By means of mechanical calculation, the clamped beam structure of open-off cut roof under roof uncut condition and the cantilever beam structure under roof cutting condition are analyzed, respectively, and the roof cutting pressure releasing principle is explained from the first weighting step and strength about mining face. Besides, the stress evolution processes of surrounding rocks under the two conditions are deduced by numerical simulation to verify the roof cutting pressure releasing effect of open-off cut roof.

(3) Taking the tested mine as an example, this paper summarizes the design, implementation process, and application effect of the OCRCPR test. Through the observation of roof collapse process at the initial stage of mining and the stress monitoring of hydraulic support in working face, it further verifies that the roof cutting technology of open-off cut can effectively shorten the first weighting step and weaken the first weighting strength of working face.

\section{Data Availability}

All the data used to support the findings of this study are available from Xingen Ma upon request.

\section{Conflicts of Interest}

The authors declare that they have no conflicts of interest.

\section{Acknowledgments}

This research was financially supported by the State Key Laboratory for GeoMechanics and Deep Underground Engineering (SKLGDUEK2020), Guizhou Department of Education Youth Talent Growth Project of China (Grant no. [2019] 162), Bijie Science and Technology Bureau Joint Fund Project (Grant nos. G[2019] no. 26), and Higher Educational Scientific Research Projects of Inner Mongolia Autonomous Region (no. NJZY21291), which are gratefully acknowledged.

\section{References}

[1] Y. Xue, "From tradition to modern times: evolution of coal mining technology in China," Journal of Hubei Polytechnic University (Humanities and Social Science), vol. 30, no. 05, pp. 7-15, 2013.

[2] Q. Huang, "Structural analysis of main roof stability during first weighting in longwall face," Chinese Journal of Rock Mechanics and Engineering, vol. 17, no. 5, pp. 521-526, 1998.

[3] X. Dai and M. Qian, "Limit analysis and calculation of first weighting interval of main roof," Journal of China University of Mining and Technology, vol. 22, no. 1, pp. 17-23, 1993.

[4] J. Wang, J. Zhang, X. Gao et al., "Fracture mode and evolution of main roof stratum above longwall fully mechanized top coal caving in steeply inclined thick coal seam (I) - initial fracture," Journal of China Coal Society, vol. 40, no. 6, pp. 1353-1360, 2015.

[5] Z. Song, "Roof deep-hole pre-blasting technology of first mining face in Suancigou colliery," Coal Mining Technology, vol. 15, no. 4, pp. 103-105, 2010.

[6] Y. Wang, L. Wang, Z. Huang et al., "Preventing cock burst based on cutting hole and breaking roof blasting technology," Safety in Coal Mine, vol. 47, no. 12, pp. 133-136, 2016.

[7] B. Junqi, "Study on deep hole pre-cracking blasting technology in open cut eyes of full mechanized caving face in 
special thick seam," Coal Mine Modernization, vol. 147, no. 6, pp. 123-125, 2018.

[8] M. He, Z. Song, A. Wang et al., "Theory of longwall mining by using roof cutting shortwall team and 110 method," Coal Science \& Technology Magazine, vol. 1, no. 1, pp. 1-9, 2017.

[9] G. Pengfei, K. Ye, Z. Tao et al., "Experimental study on key parameters of bidirectional cumulative tensile blasting with coal-containing composite roof," KSCE Journal of Civil Engineering, vol. 2, 2021.

[10] M. Yun, H. Zheng, T. Li et al., "Support design and mine pressure measurement of 1102 working face in Qiuji Coal Mine," Safety in Coal Mines, vol. 52, no. 3, pp. 127-132, 2021.

[11] Z. Zhang, M. Deng, J. Bai, X. Yu, Q. Wu, and L. Jiang, "Strain energy evolution and conversion under triaxial unloading confining pressure tests due to gob-side entry retained," International Journal of Rock Mechanics and Mining Sciences, vol. 126, Article ID 104184, 2020.

[12] D. He, Research on the Pre-splitting Blasting Weakening Mechanism of the Hard Roof under the Deep Environment, China university of mining technology, Xuzhou, China, 2015.

[13] X. Yang, Di Yuan, H. Xue et al., "Research on roof cutting and pressure releasing technology of cumulative blasting in deep and high stress roadway," Geotechnical and Geological Engineering, vol. 39, 2021.

[14] X. Sun, X. Liu, G. Liang et al., "Key Parameters of gob-side entry retaining formed by roof cut and pressure releasing in thin coal seams," Chinese Journal of Rock Mechanics and Engineering, vol. 33, no. 7, pp. 1449-1456, 2014.

[15] X. Ma, M. He, J. Sun, H. Wang, X. Liu, and E. Zhen, "Neural network of roof cutting blasting parameters based on mines with different roof conditions," Energies, vol. 11, no. 12, p. 3468, 2018.

[16] Z. Zhang, M. Deng, X. Wang, W. Yu, F. Zhang, and V. D. Dao, "Field and numerical investigations on the lower coal seam entry failure analysis under the remnant pillar," Engineering Failure Analysis, vol. 115, p. 104638, 2020.

[17] S. Zhang, The Theory and Practice Research on Deep Hole Presplit Blasting of Open-Off Cut of Fully Mechanized Caving Face, Taiyuan University of Technology, Taiyuan, China, 2014.

[18] G. Ramesh and R. Karpurapu, "Laboratory and numerical studies on the performance of geocell reinforced base layer overlying soft subgrade," International Journal of Geosynthetics and Ground Engineering, vol. 7, 2021.

[19] K. V. Amit and T. N. Singh, "Modeling of a jointed rock mass under triaxial conditions," Arabian Journal of Geosciences, vol. 3, pp. 91-103, 2010.

[20] M. He, X. Ma, J. Wang et al., "Feature analysis of working face strata pressure with roof cutting pressure releasing in medium-thick seam and compound roof condition," Chinese Journal of Rock Mechanics and Engineering, vol. 37, no. 11, pp. 1-11, 2018.

[21] J. Wang, Y. Liu, X. Ma et al., "Technology of roof cutting and entry retaining in fully-mechanized working face of Tashan Coal Mine," Coal Science and Technology, vol. 47, no. 2, pp. 27-34, 2019.

[22] C. Hu, X. Yang, R. Huang et al., "Presplitting blasting the roof strata to control large deformation in the deep mine roadway," Advances in Civil Engineering, vol. 2020, Article ID 8886991, 15 pages, 2020.

[23] S. Wang, "Experimental study on roof-cutting-and-pressurerelief technology with hydraulic fracturing in retaining roadway along goaf," Jiangxi Coal Technology, vol. 1, pp. 25-30, 2021.
[24] J. Hu, Y. Wang, Z. Ma et al., "Experimental and numerical analysis of rock burst tendency and crack development characteristics of tianhu granite," Geofluids, vol. 2021, Article ID 6681261, 12 pages, 2021.

[25] Z. Zhang, M. Deng, J. Bai, S. Yan, and X. Yu, "Stability control of gob-side entry retained under the gob with close distance coal seams," International Journal of Mining Science and Technology, vol. 31, no. 2, pp. 321-332, 2021.

[26] X. Ma, Research on Key Technologies and Rock Pressure Law of 110 Mining Method with Compound Hard Roof in Tashan Coal Mine, China University of Mining and Technology, Beijing, China, 2019. 